\title{
IN VITRO BIOLOGICAL PROPERTIES OF CRUDE METHANOL EXTRACT FROM MUSHROOM; FLAMMULINA VELUTIPES (GOLDEN NEEDLE MUSHROOM)
}

\author{
BAJAREE JANTRAPANUKORN ${ }^{1 *}$, PANNAPA POWTHONG ${ }^{1}$, CHITRADEE LUPRASONG ${ }^{2}$
}

${ }^{1}$ Faculty of Medical Technology, Rangsit University, Pathum Thani, 12000, Thailand. ${ }^{2}$ Sun Herb, Thai, Chinese Manufacturing, Rangsit University, Pathum Thani, 12000, Thailand. Email: NubaMT@gmail.com

Received: 27 February 2018, revised and accepted: 07 July 2018

\section{ABSTRACT}

Objectives: The objectives of this study were to investigate the in vitro biological effect of the methanolic crude extract received from edible mushrooms; Flammulina velutipes on anti-inflammatory, antioxidant activity, anti-lipid peroxidation (LPO), antimicrobial activity, and anticancer activity. The scientific result obtained here was possibility of developing this variety as an ingredient in health/medical food purposes as well as a functional food.

Methods: In this study, the methanol crude extract of $F$. velutipes has been performed and in vitro pharmacological properties such as anti-inflammatory, antioxidant activity, anti-LPO, antimicrobial activity, and anticancer activity were evaluated.

Results: The results revealed that anti-inflammatory activity of crude extract was very significant with $79.81 \pm 0.87 \%$ of the dose-dependent manner. Antioxidant and anti-low-density lipoprotein (LDL) peroxidation activity of the extract showed its capacity of free radical scavenging with highlevel antioxidant compounds and lipid preventive effects $(2,2$-diphenyl-1-picrylhydrazyl: 79.81 $\pm 0.01 \%$, total phenol: $991.10 \pm 0.01 \mu$ gallic acid equivalents/0.1 g dry matter, $\mathrm{H}_{2} \mathrm{O}_{2} .93 .27 \pm 0.05 \%$, LPO: $33.33 \pm 0.00 \%$, and LDL: $57 \pm 0.03 \%$, respectively). Analysis has also demonstrated that the methanolic extract of $F$. velutipes provided an antimicrobial activity to ESBL-producing Klebsiella pneumoniae. Moreover, $F$. velutipes extract showed a growth inhibitory effect in HepG2 cells with the $50 \%$ inhibitory concentration $\left(\mathrm{IC}_{50}\right.$ ) value $\mathrm{IC}_{50}=8.25 \pm 7.59 \mu \mathrm{g} / \mathrm{ml}$.

Conclusion: This indicated that crude extract from F. velutipes was scientifically proved as a potential source of therapeutic agent and be able to utilize as a functional ingredient for healthy or supplement food.

Keywords: Flammulina velutipes, Methanol crude extract, Pharmacological properties, Antioxidant, Antimicrobial, Antitumor.

(C) 2018 The Authors. Published by Innovare Academic Sciences Pvt Ltd. This is an open access article under the CC BY license (http://creativecommons. org/licenses/by/4. 0/) DOI: http://dx.doi.org/10.22159/ajpcr.2018.v11i9.25509

\section{INTRODUCTION}

Recently, there has been the most considerable in the use of natural antioxidants as food supplements and scientific interest in fungal biomolecules as antioxidants [1-4]. Although the chemical nature of such compounds is still unclear, phenolic compounds and non-phenolic compounds including terpenoids and polysaccharides have also been designated as major naturally occurring antioxidant components found in medicinal mushrooms [5-7].

Edible mushrooms, Flammulina velutipes is one of the most popular edible mushrooms in Asia. It contained a lot of bioactive compounds such as polysaccharides, protein-glucan complex, and sterols and lectins of medicinal and pharmaceutical properties [8]. F. velutipes is well known for promoting human health and scientifically proved for its important natural resources of immunomodulating, antitumor, antioxidant, thrombolytic, fibrinolytic, antibacterial, antifungal, antiviral, haploidic, and mitogenic agents [9]. However, drug action and dose consumption of the extracts were varied since the differentiation of extraction technique and active ingredients consisting in it.

Our objective was to investigate the in vitro biological effect of the methanolic crude extract received from $F$ velutipes on anti-inflammatory, antioxidant activity, anti-lipid peroxidation (LPO), antimicrobial activity, and anticancer activity. The scientific result obtained here was possibility of developing this variety as an ingredient in health/medical food purposes.

\section{MATERIALS AND METHODS}

\section{Mushroom material}

Fruit bodies of $F$. velutipes (Curtis: Fries) were purchased from the local market Pathum Thani, Thailand. The botanical identity of the plant specimen of $F$. velutipes was confirmed by a taxonomist at Sun Herb, Thai, Chinese Manufacturing, Rangsit University. It was authenticated to be F. velutipes belonging to family Physalacriaceae. Thereafter, the mushroom was cleaned, cut into small pieces and was subjected to dry at $40^{\circ} \mathrm{C}$ for 15-20 h. The dry material was ground into powder and stored in air-tight plastic bag in a desiccator at room temperature for further analysis.

\section{Preparation of $\boldsymbol{F}$. velutipes crude extract}

For extraction, methanol extraction has been conducted with the ratio of sample of mushroom powders: Methanol equal to $1: 10$ under $37^{\circ} \mathrm{C}$ for 5 days. Solid has been discarded by filtered through Whatman No. 1 filter paper. The filtrate was subjected to rotary evaporator for ethanol removal, then crude extract of $F$. velutipes has been received. The crude was redissolved in dimethyl sulfoxide (DMSO) at the concentration of $1 \mathrm{~g} / \mathrm{ml}$. Crude extract was kept in glass bottle under $-20^{\circ} \mathrm{C}$ along this experiment.

\section{Microorganisms and chemicals}

Microorganisms used in this study were both Gram-positive and Gramnegative, for example, two strains of multidrug-resistant Acinetobacter baumannii (MDR I and MDR II), vancomycin-resistant Enterococcus faecalis, ESBL-producing Escherichia coli, ESBL-producing E. coli P174, ESBL-producing Klebsiella pneumoniae, two strains of multidrugresistant Pseudomonas aeruginosa (MDR I and MDR II), and two strains of methicillin-resistant Staphylococcus aureus (MRSA I and MRSA II). All chemicals used were analytical grade.

\section{Anti-inflammatory assay of $\boldsymbol{F}$. velutipes crude extract}

Anti-inflammatory was determined as the inhibition effect on protein denaturation using modified Mizushima and Kobayashi (1968) method [10]. Crude extract of $F$. velutipes has been serial 2-fold diluted to the concentration of $625,1250,2500,5000$, and $10,000 \mu \mathrm{g} / \mathrm{ml}$ in distill 
water. $100 \mu \mathrm{l}$ of each concentration mixed with $500 \mu \mathrm{l}$ of $1 \%$ bovine serum albumin, then let the mixtures stand at ambient temperature for $10 \mathrm{~min}$. The mixture was heated at $51^{\circ} \mathrm{C}$ for $20 \mathrm{~min}$ and cooled at room temperature. The absorbance was measured at $660 \mathrm{~nm}$. Acetylsalicylic acid was used as positive control. Inhibited percent was calculated as follows:

$\%$ inhibition $=100-\frac{(\mathrm{A} 1-\mathrm{A} 2)}{\mathrm{A} 0} \times 100$

Where, A1, A2, and A0 were absorbance of sample, product control, and positive control, respectively.

\section{Antioxidant assay of $\boldsymbol{F}$, velutipes crude extract}

2, 2-diphenyl-1-picrylhydrazyl (DPPH) free radical scavenging assay

The free radical scavenging activities of the extracts were measured using DPPH [11]. Briefly, extract concentration of $625-10,000 \mu \mathrm{g} / \mathrm{ml}$ in $100 \mu \mathrm{l}$ methanol was mixed with $100 \mu \mathrm{l} \mathrm{ml}$ of methanolic solution containing $0.2 \mathrm{mM}$ of DPPH (DPPH, Sigma). The mixture was shaken vigorously and left to stand for $30 \mathrm{~min}$ in the dark, and the absorbance was then measured at $517 \mathrm{~nm}$ against a blank. The calibration curve was also established using Vitamin C equivalent antioxidant capacity by solution of L-ascorbic acid in methanol. The capability to scavenge the DPPH radical was calculated using the following equation:

DPPH scavenging effect $(\%)=\left[1-\left(A_{1} / A_{0}\right)\right] \times 100$

Where, $A_{0}$ was the absorbance of the control reaction and $A_{1}$ was the absorbance in the presence of the sample.

\section{Folin-Ciocalteu colorimetric assay}

Total phenolic compounds were determined using Folin-Ciocalteu's method [12]. Briefly, extract concentration of $625-10,000 \mu \mathrm{g} / \mathrm{ml}$ in $20 \mu \mathrm{l}$ ethanol was mixed with $100 \mu \mathrm{lml}$ of Folin-Ciocalteu's reagent $(100 \mu \mathrm{l}$, previously diluted with water $1: 10, v / v$ ). From the resulting mixture, $80 \mu \mathrm{l}$ of $2 \%$ aqueous sodium carbonate was added. The mixture was incubated for $30 \mathrm{~min}$; absorbance was measured at $765 \mathrm{~nm}$ against the blank. The content of total phenol was calculated on the basis of the calibration curve of gallic acid, and the results were expressed as $\mu \mathrm{g}$ of gallic acid equivalents (GAEs) per mg of extract.

\section{Hydrogen peroxide scavenging activity}

The ability to eradicate hydrogen peroxide was determined according to Halliwell et al. [13]. An aliquot $(850 \mu \mathrm{l})$ of $F$. velutipes, crude extract at different dilutions $(625-10,000 \mu \mathrm{g} / \mathrm{ml})$, was added to $150 \mu \mathrm{L}$ of $4 \mathrm{mM}$ hydrogen peroxide solution in phosphate buffer $(0.1 \mathrm{M}, \mathrm{pH} 7.4)$. The solution was incubated for $10 \mathrm{~min}$ and the absorbance measurement was performed at $230 \mathrm{~nm}$ where butylated hydroxytoluene was used as positive control.

\section{Anti-LPO}

Thiobarbituric acid (TBA), reactant substances assay, was used to analyze the inhibition of lipid peroxidase as described by Ruberto et al. [14], with some modification. Briefly, diluted eggyolk to $10 \%$ (w/v) with KCL solution was added to $50 \mu \mathrm{l}$ of different concentrations F. velutipes crude extract. The addition of $20 \%$ acetic acid (pH 3.5) 300 $\mu \mathrm{l}$ and TBA $300 \mu \mathrm{l}$ into the previous solution then mixed with vortex mixer. The mixtures were incubated at $95^{\circ} \mathrm{C}$ for $1 \mathrm{~h}$ and left them to cool at ambient temperature. Adding $750 \mu \mathrm{l}$ of butanol then centrifugation at $3000 \mathrm{rpm}$ for $10 \mathrm{~min}$. Supernatant was absorbance measurement using an ELISA reader at $532 \mathrm{~nm}$.

Antioxidative low-density lipoprotein (LDL) ability was also determined. Briefly, $9 \mu \mathrm{l}$ of human LDL were mix with $191 \mu \mathrm{l}$ of $10 \mathrm{mM}$ ferrous sulfate and $100 \mu \mathrm{l}$ of $F$. velutipes crude extract at different dilution $(625-10,000 \mu \mathrm{g} / \mathrm{mL})$. After that, $15 \%$ trichloroacetic acid 500 $\mu \mathrm{L}$ and $1 \%$ TBA $1 \mathrm{ml}$ were added. The mixtures were incubated at $100^{\circ} \mathrm{C}$ for $10 \mathrm{~min}$. Then, cool by left them to stand at ambient temperature.
Pipette $300 \mu \mathrm{l}$ of the mixtures into microtiter plate and measured the absorbance at $532 \mathrm{~nm}$ using an ELISA reader, and $\mathrm{CuSO}_{4}(\mathrm{pH} 7.4)$ has been applied as blank.

\section{Antimicrobial test of $\boldsymbol{F}$. velutipes crude extract}

Antimicrobial activity was tested by agar well diffusion method. Gramnegative and Gram-positive bacteria mentioned above were used for antimicrobial test. Reculture those respective bacteria from freezing vials on nutrient agar and adjusted its turbidity using spectrophotometer measurement at $625 \mathrm{~nm}$ to achieve concentration of $1.5 \times 10^{8} \mathrm{CFU} / \mathrm{ml}$ in a sterile $0.85 \% \mathrm{NaCl}$ solution. $100 \mu \mathrm{l}$ of test organism was applied to the surface of Muller-Hinton agar using sterile cotton swab. $6 \mathrm{~mm}$ diameter wells in agar were made using a sterile cork borer. $30 \mu \mathrm{l}$ of different dilutions of $F$. velutipes crude extract $(625-10,000 \mu \mathrm{g} / \mathrm{ml})$ were added to the wells. Similarly, $30 \mu$ l of nutrient broth and gentamycin were used as negative control and positive control. The plates were incubated at $35 \pm 2{ }^{\circ} \mathrm{C}$ for $24 \mathrm{~h}$, and the diameter of inhibition zone around the well was measured using a scale. All experiments were repeated 3 times.

\section{Cell lines and culture medium} Chemicals

3-(4,5-dimethylthiazol-2-yl)-5-diphenyltetrazolium bromide (MTT), fetal bovine serum (FBS), phosphate-buffered saline (PBS), Dulbecco's modified Eagle's medium (DMEM), and trypsin were obtained from Sigma-Aldrich Co., St. Louis, USA. Ethylenediaminetetraacetic acid (EDTA), DMSO, and propanol were obtained from Merck Ltd., USA.

Human, liver hepatocellular cells (HepG2) stock cells were cultured in DMEM supplemented with $10 \%$ inactivated FBS, penicillin (100 IU/ml), in a humidified atmosphere of $\% \mathrm{CO}_{2}$ at $37^{\circ} \mathrm{C}$ until confluent. The cells were dissociated with a trypsin phosphate solution $(0.2 \%$ trypsin, $0.02 \%$ EDTA in PBS). The stock cultures were grown in $25 \mathrm{~cm}^{2}$ culture flasks, and all experiments were carried out in 96 microtiter plates (Nunc. Ltd., USA).

\section{Preparation of test solutions}

For cytotoxicity studies, the crude extract from $F$. velutipes was dissolved in DMSO and volume was made up with non-supplemented DMEM and sterilized by filtration. Serial dilutions were prepared for this for carrying out cytotoxic studies.

\section{Cytotoxicity assay}

The MTT assay was performed as described by Cardile et al. [15]. The viability of the cell was assessed by MTT assay, which is based on the reduction of MTT by the mitochondrial dehydrogenase of intact cells to a purple formazan product. Cells were seeded in 96-well microtiter plates $\left(5 \times 10^{3}\right.$ cells/well in $100 \mu \mathrm{l}$ medium $)$ and routinely cultured in a humidified incubator at $37^{\circ} \mathrm{C}$ in $5 \% \mathrm{CO}_{2}$ for $24 \mathrm{~h}$. The extracts were added in serial concentrations such as 7.81, 15.63, 31.25, 62.5, 125, 250, 500, $1000,10,000$, and $100,000 \mu \mathrm{g} / \mathrm{ml}$ and Triton X ( 1 and $2 \%$ ) was used as positive control. The plate was reincubated for $24 \mathrm{~h}$. Then, the medium was discarded and $30 \mu \mathrm{l}$ of MTT dye solution ( $5 \mathrm{mg} / \mathrm{ml}$ in PBS) was added to every well and reincubated for $4 \mathrm{~h}$. After removing untransformed MTT reagent, $100 \mu \mathrm{l}$ of DMSO was added to dissolve the formed formazan crystals. Amount of formazan was determined by measuring the absorbance at $570 \mathrm{~nm}$ using an enzyme-linked immunosorbent assay plate reader. All experiments were carried out 3 times.

\section{Statistical analysis}

All experimental results were carried out in triplicate and were expressed as average of three analyses \pm SD (standard deviation) using the SPSS version 22.

\section{RESULTS AND DISCUSSION}

The need for a new source of natural bioactive compounds, in general, comes from the increasing health promotion regimen. The present study was pointing out to $F$. velutipes due to their wide ubiquity in nature compound, leading the production of various therapeutic properties, 
i.e.,T anti-inflammatory, antioxidant, antimicrobial, and antitumor.

In this study, F. velutipes crude extract has been subjected for its potent of protein denature inhibition. BSA was denatured by heat treatment, and different doses of the extract have been tested for preventing BSA denaturation which presented in Fig. 1. From the data, it was shown that the inhibition of BSA denaturation was dose-dependent. At the initial concentration $(625 \mu \mathrm{g} / \mathrm{ml}), F$. velutipes demonstrated inhibition effect of BSA denaturation more than $50 \%$ and increased to $79.81 \pm 0.01 \%$ when the dose reaches $10,000 \mu \mathrm{g} / \mathrm{ml}$. Denaturation of proteins is the main cause of inflammation [16]. Therefore, ability

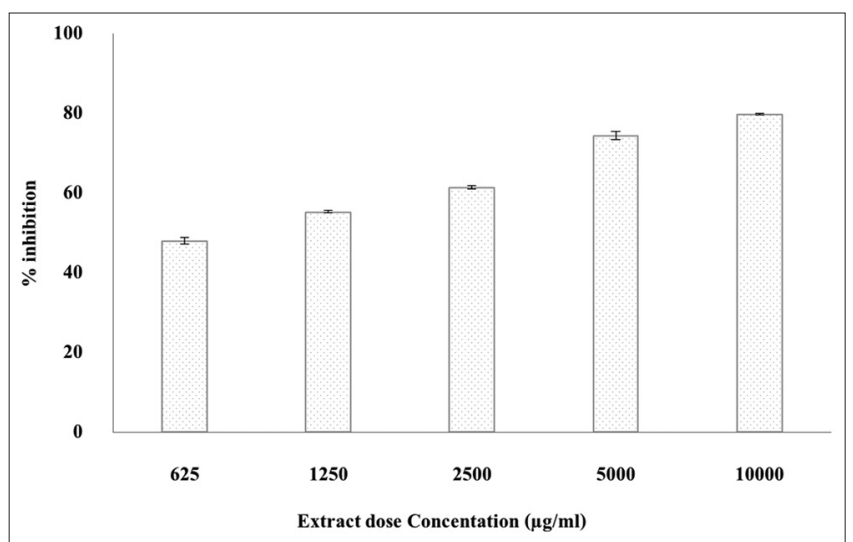

Fig. 1: Effect of Flammulina velutipes crude extract on preventing of BSA denaturation

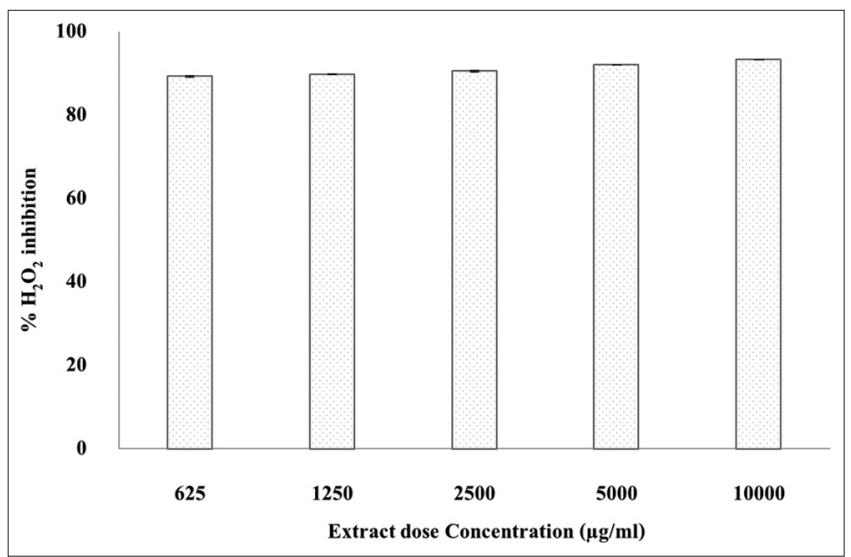

Fig. 2: Effect of Flammulina velutipes crude extract on hydroxyl radicals scavenging ability of preventing protein denaturation suggesting that $F$. velutipes crude extract possessed anti-inflammatory activity undoubtedly. The ability to inhibit BSA denaturation which composed of two binding sites which are aromatic tyrosine-rich and aliphatic threonine and lysine residue region, those therapeutic compounds existing in the extract might activate the tyrosine motif rich receptor dually with threonine that regulates signal transduction biological pathways for their overall biological action $[17,18]$. It is also noteworthy that those compounds which react to aliphatic lysine residue on BSA may possess antioxidant or anticancer properties the same as polyphenol substances [18-20].

To determine $F$. velutipes crude extract for its antioxidant activity, numerous methods were used to yield the complete antioxidant profile of respective sample, and the result shown in Table 1 and Figs. 2-3.

Total phenolic compound of crude extract shown high value with $991.10 \pm 0.01 \mu \mathrm{g}$ GAE/0.1 g dry matter. This result was similar to Sławińska et al. who revealed the same finding that $F$. velutipes extract with ethanol showed the highest value as $4.73 \pm 0.13-6.31 \pm 0.34 \mathrm{mg} \mathrm{GAE} / \mathrm{g}$ of extract [21]. Moreover, F. velutipes crude extract possessed DPPH free radical scavenging activity of $68.42 \pm 3.03 \%$, which slightly higher than the finding reported by Sławińska et al. [21] and Milovanovic [22].

Hydroxyl radicals, the most reactive radicals generated during aerobic metabolism, are the form of a number of reactive oxygen species such as superoxide anion, hydrogen peroxide, and nitric oxide which damage biological molecules [23-25]. Results on hydroxyl radical scavenging of F. velutipes crude extract shown in Fig. 2 and revealed that scavenging activity of the extract was increased when its dose was higher. The scavenging activity of the extract at $10,000 \mu \mathrm{g} / \mathrm{ml}$ was greatly high as over $93.27 \pm 0.05 \%$. Two mechanisms of antihydroxyl radicals were proposed; one is to prevent hydroxyl radicals generating through ligate to metal ions and two, scavenge the generated hydroxyl free radical [23]. This might suggest that $F$. velutipes crude extract also carried those mentioned antihydroxyl radical activity. Some similar findings showed a similar trend for DPPH from some selected indigenous wild edible

Table 1: Scavenging effect on DPPH free radical, total antioxidant, and total phenolic compound presented in $0.1 \mathrm{~g} / \mathrm{ml}$ F. velutipes crude extract

\begin{tabular}{ll}
\hline Antioxidant assay & Average \pm SD \\
\hline Total phenolic compound & $991.10 \pm 0.01$ \\
( $\mu$ g GAE/0.1 g dry matter) & \\
DPPH scavenging activity $(\%)$ & $68.42 \pm 3.03$ \\
Total antioxidant & $50.06 \pm 5.50$ \\
$(\mu \mathrm{g}$ of Vitamin C equivalent/0.1 g dry matter) & \\
\hline
\end{tabular}

DPPH: 2, 2-Diphenyl-1-picrylhydrazyl, F. velutipes: Flammulina velutipes, GAE: Gallic acid equivalents

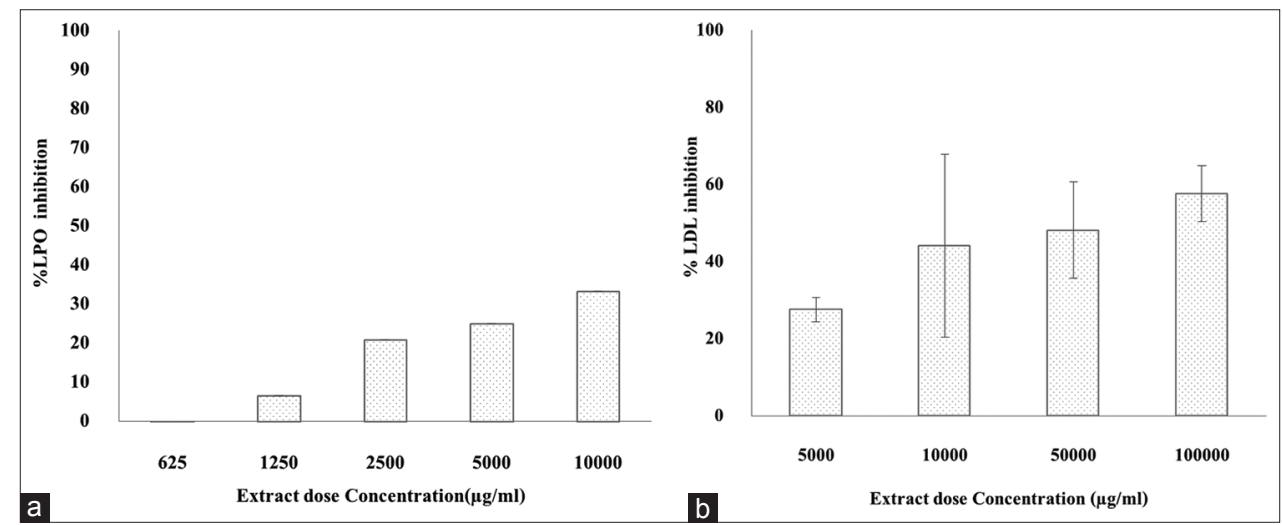

Fig. 3: Effect of Flammulina velutipes crude extract as an anti-lipid oxidation; (a) Inhibition ability on lipid peroxidation, (b) Inhibition ability on low-density lipoprotein 


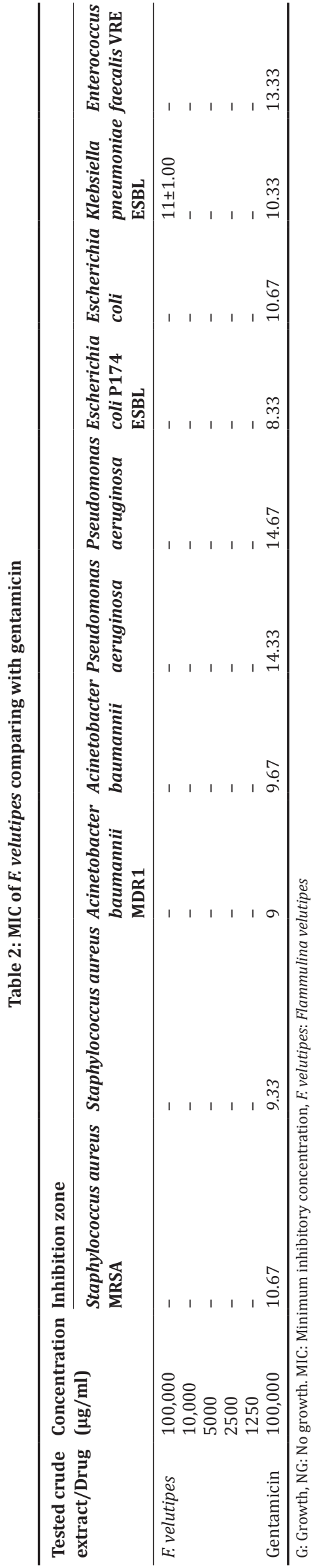

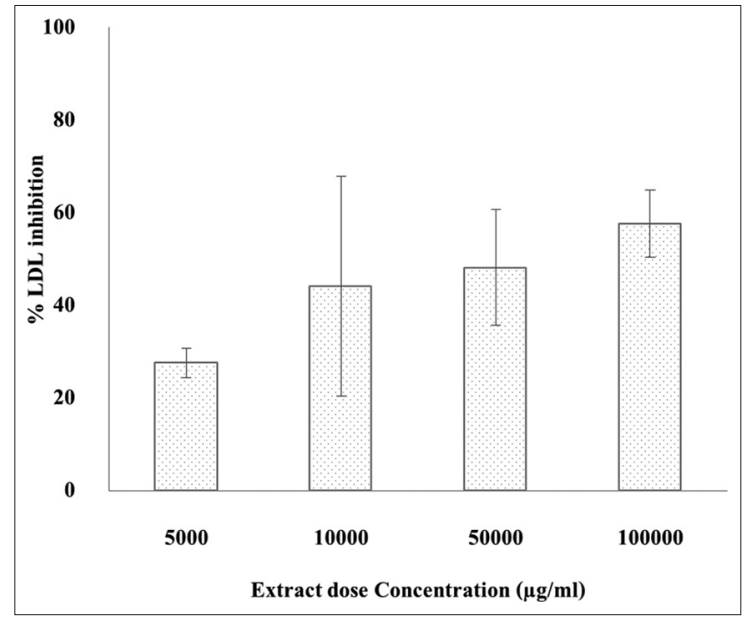

Fig. 4: Cytotoxicity effect of Flammulina velutipes crude extract to HepG2 (liver carcinoma) cell line

mushrooms such as Termitomyces group, Russula, and Volvariella sp. in Eastern India as $61 \%$ to as high as $94 \%$ [26].

Not only in aqueous matrix has the oxidative reaction but also occurred in lipid layer which LPO has been regarded as the main cause of damaging cellular component and fragmentation of connective tissues [27,28]. From Fig. 3a, it was appeared that $F$. velutipes crude extract contained LPO and LDL inhibition property as dose-dependent manner. An extract dose at $10,000 \mu \mathrm{g} / \mathrm{mL}$ performed $33.33 \pm 0.00 \%$ of LPO inhibition.

Oxidized LDL is recognized as the cause of lipid accumulated on arterial walls and lead to atherosclerosis-related disease [29,30]. F. velutipes crude extract also expressed high potential of LDL oxidative inhibition property which showed the value as $57 \pm 0.03 \%$ of LDL inhibition was received at an extract dose of $10,000 \mu \mathrm{g} / \mathrm{ml}$ (Fig. 3b). Similar results were found that $F$. velutipes crude extract by methanol can inhibit the formation of thiobarbituric acid reactive substances by use human LDL as a lipid source with value $48.71 \%$, at $1 \mathrm{mg} / \mathrm{ml}$ concentration [31].

In the present work, antimicrobial property verified by well diffusion showed the potential of the F. velutipes crude extract was characterized against both Gram-negative and Gram-positive microorganisms where gentamicin was used as positive control, and the results were shown in Table 2. Among the tested bacteria, F. velutipes crude extract only at $10,000 \mu \mathrm{g} / \mathrm{ml}$ demonstrated as the least concentration to inhibit only ESBL-producing $K$. pneumoniae with the inhibition zone as $11 \pm 1.00 \mathrm{~mm}$. Nicolcioiub et al. also demonstrated that the F. velutipes crude extract by ethanol can inhibit growth of Bacillus subtilis subsp. Spizizenii ATCC 6633, S. aureus ATCC 6538, and P. aeruginosa ATCC 9027 with inhibition zone between 10 and $20 \mathrm{~mm}$ [32]. Similarly, previously reported showed that the methanolic extract of white button mushroom (Agaricus bisporus) displays antimicrobial activity against $P$. aeruginosa and S. aureus with a high level of inhibition zone [33].

The biological activity of any phytocompounds depends on the type of chemical composition and the concentration of active constituents as well as types and developmental stages of the cancer [34]. The screening of $F$. velutipes crude extract for their anticancer properties used cell-based assays and established cell lines, in which the cytotoxic effects of mushroom extracts could be measured. MTT assay is a non-radioactive, fast, and economical assay widely used to quantify cell viability and proliferation. MTT is a yellow water-soluble tetrazolium salt. Metabolically active cells are able to convert the dye to water-insoluble dark blue formazan by reductive cleavage of the tetrazolium ring [35]. The result of our study revealed that the exposure of crude extract from $F$. velutipes at different concentrations such as 7.81, $15.63,31.25,62.5,125,250,500,1000,10,000$, and $100,000 \mu \mathrm{g} / \mathrm{ml}$ for $24 \mathrm{~h}$ resulted in decrease of cell proliferation in a dose-dependent manner. The percentage of inhibitory concentration $50 \%\left(\mathrm{IC}_{50}\right)$ inhibition of cell 
proliferation was found to be initiated at the concentration of $8.25 \pm 7.59 \mu \mathrm{g} /$ $\mathrm{ml}$ (Fig. 4). It was clearly confirmed that the crude extract from $F$. velutipes was effective and can be used as alternative chemotherapy cancer. Another report from Milovanovic et al. was shown that crude extract from $F$. velutipes has a low cytotoxic activity against both HeLa and LS174 cell line with $\mathrm{IC}_{50}$ as $259.69 \pm 0.70 \mu \mathrm{g} / \mathrm{mL}$ and $338.47 \pm 0.97 \mu \mathrm{g} / \mathrm{ml}$, respectively [22].

\section{CONCLUSION}

The results obtained in the present work denote that wild-growing edible mushrooms; $F$ velutipes may constitute a good source of healthy compounds or phenols intake in the diet. The results revealed that the F. velutipes crude extract possessed various pharmacological properties (in vitro evaluation), for example, antimicrobial, anti-inflammatory, antioxidant, and antitumor, which expressed against both free radicals in aqueous and lipid matrix. Due to these characteristics, F. velutipes could be considered as a complement in the diet for the benefits they present and may use as a potential natural ingredient to improve the therapeutic effects of medication or supplement food for some diseases.

\section{ACKNOWLEDGMENT}

The authors would like to express our sincere gratitude and profound appreciation for the mushroom sample which providing from Sun Herb, Thai Chinese Manufacturing, Ransit University. We also would like to thank Financial support from the faculty of medical technology, Rangsit University, is gratefully acknowledged.

\section{AUTHOR'S CONTRIBUTIONS}

All authors contributed extensively to the work presented in this paper. Bajaree Jantrapanukorn designed, performed experiments, analyzed data, and wrote the paper; Pannapa Powthong performed experiments, gave conceptual advice, and revised the manuscript and analyses data; Chitradee Luprasong gave technical support and revised the manuscript. All authors discussed the results and implications and commented on the manuscript at all stages.

\section{CONFLICTS OF INTEREST}

The authors declare that there are no conflicts of interest regarding the publication of this paper.

\section{REFERENCES}

1. Mau JL, Lin HC, Chen CC. Antioxidant properties of several medicinal mushrooms. J Agric Food Chem 2002; 50:6072-77.

2. Dubois V, Breton S, Linder M, Fanni J, Parmentier M. Fatty acid profiles of 80 vegetables oils with regard to their nutritional potential. Eur J Lipid Sci Technol 2007;109:710-32.

3. Elmastas M, Isildak O, Turkekul I, Temur N. Determination of antioxidant activity and antioxidant compounds in wild edible mushrooms. J Food Comp Anal 2007;20:337-45.

4. Turkoglu A, Duru ME, Mercan N, Kivrak I, Gezer K. Antioxidant and antimicrobial activities of Laetiporus sulphureus (Bull) Murrill. Food Chem 2007; 101:267-73

5. Puttaraju NG, Venkateshaiah SU, Dharmesh SM, Urs SM, Somasundaram R. Antioxidant activity of indigenous edible mushrooms. J Agric Food Chem 2006;54:9764-72.

6. Leon F, Quintana J, Rivera A, Estevez F, Bermejo J. Lanostanoid triterpenes from Laetiporus sulphureus and apoptosis induction on HL60 human myeloid occurring cells. J Nat Prod 2004;67:2008-11.

7. Tseng YH, Yang JH, Mau JL. Antioxidant properties of polysaccharides from Ganoderma tsugae. Food Chem 2008;107:732-8.

8. Yang W, Fang Y, Liang J, Hu Q. Optimization of ultrasonic extraction of Flammulina velutipes polysaccharides and evaluation of its acetylcholinesterase inhibitory activity. Food Res Int 2011;44:1269-75.

9. Leung MY, Fung KP, Choy YM. The isolation and characterization of an immunomodulatory and antitumor polysaccharide preparation from Flammulina velutipes. Immunopharmacology 1997;35:255-63.

10. Mizushima Y, Kobayashi M. Interaction of anti-inflammatory drugs with serum proteins, especially with some biologically active proteins. J Pharm Pharm 1968;20:169-73.

11. Jung BK, Jong BK, Kang JC, Gabriele MK, Anthony DW. Antioxidant activity of 3, 4, 5-trihydroxybenzaldehyde isolated from Geum japonicum. J Food Drug Anal 2006;14:190-3.
12. Singleton VL, Orthofer R, Lamuela-Raventos RM. Analysis of total phenols and other oxidation substrates and antioxidants by means of Folin-Ciocalteu reagent. Methods Enzymol 1999;29:152-78.

13. Halliwell B, Gutteridge JM, Arugma OI. The deoxyribose method: A simple "Test-Tube" assay for determination of rate constants for reactions of hydroxyl radicals. Analy Biochem 1987; 165:215-9.

14. Ruberto G, Baratta MT, Deans SG, Dorman HJ. Antioxidant and antimicrobial activity of Foeniculum vulgare and Crithmum maritimum essential oils. Planta Med 2000;66:687-93.

15. Cardile V, Renis M, Scifo C, Lombardo L, Gulino R, Mancari B, et al. Behaviour of the new asbestos amphibole fluor-edenite in different lung cell systems. Int J Biochem Cell Biol 2004;36:849-60.

16. Perumal R, Dey A, Manavalan R, Prakasam K, Jayachandran E, Sreenivasa GM. Inhibition of albumin denaturation and anti inflammatory activity of furfuryl substituted pyrimidinoimidazolinones. Int J Chem Sci 2008;6:2016-22

17. Rosner H, Williams LA, Jung A, Kraus W. Disassembly of microtubules and inhibition of neurite outgrowth, neuroblastoma cell proliferation, and MAP kinase tyrosine dephosphorylation by dibenzyl trisulphide. Biochim Biophys Acta 2001;1540:166-77.

18. Williams LA, Roesner H, Conrad J, Moeller W, Beifuss U, Chiba K, et al. Selected secondary metabolites from the phytolaccaceae and their biological/ pharmaceutical significance. Recent Res Dev Phytochem 2002;6:13-68.

19. Kawabata T, Packer L. Alpha-lipoate can protect against glycation of serum albumin, but not low density lipoprotein. Biochem Biophys Res Commun 1994;203:99-104.

20. Williams LA, Vasquez EA, Milan PP, Zebitz C, Kraus W. In vitro antiinflammatory and antimicrobial activities of phenylpropanoids from Piper betle L. (Piperaceae). In: Rauter AP, Palma FB, Justino J, Araújo ME, dos Santos SP, editors. Natural Products in the New Millennium: Prospects and Industrial Application. Proceedings of the Phytochemical Society of Europe. Vol. 47. Dordrecht: Springer; 2002. p. 221-7.

21. Sławińska A, Radzki W, Kalbarczyk J. Antioxidant activities and polyphenolics content of Flammulina velutipes mushroom extracts. Herb Pol 2013;59:26-35.

22. Milovanovic' I, Stanojkovic' T, Stajic' M, Vukojevic'J, Kneževic' A. The effect on biological activity of Flammulina velutipes. Ital J Food Sci 2015;27:1-7.

23. Zhang Z, Lv G, Pan H, Fan L, Soccol CR, Pandey A. Production of powerful antioxidant supplements via solid-state fermentation of wheat (Triticum aestivum Linn.) by Cordyceps militaris. Food Technol Biotechnol 2012;50:32-9.

24. Badmus JA, Adedosu TO, Fatoki JO, Adegbite VA, Adaramoye OA, Odunola OA. Lipid peroxidation inhibition and antiradical activities of some leaf fractions of Mangifera indica. Acta Pol Pharm 2011;68:23-9.

25. Siddhuraju P, Becker K. The antioxidant and free radical scavenging activities of processed cowpea (Vigna unguiculata (L.) Walp. seed extracts. Food Chem 2007;101:10-9.

26. Tripathy SS, Rajoriya A, Mahapatra A, Gupta N. Biochemical and antioxidant properties of wild edible mushrooms used for food by tribal of Eastern India. Int J Pharm Pharm Sci 2016;8:194-9.

27. Halliwell B, Gutteridge JM. Free Radicals in Biology and Medicine. $3^{\text {rd }}$ ed. Oxford: Oxford University Press; 1999.

28. Chance B, Sies H, Boveris A. Hydroperoxide metabolism in mammalian organs. Physiol Rev 1979;59:527-605.

29. Steinberg D, Parthasarathy S, Carew TE, Khoo JC, Witztum JL. Beyond cholesterol. Modifications of low-density lipoprotein that increase its atherogenicity. N Engl J Med 1989;320:915-24.

30. Cross CE, Halliwell B, Borish ET, Pryor WA, Ames BN, Saul RL, et al. Oxygen radicals and human disease. Ann Intern Med 1987;107:526-45.

31. Rahman MA, Abdullah N, Aminudin N. Antioxidative effects and inhibition of human low density lipoprotein oxidation in vitro of polyphenolic compounds in Flammulina velutipes (golden needle mushroom). Oxid Med Cell Longev 2015;2015:1-10.

32. Nicolcioiu MB, Popa G, Matei F. Antimicrobial activity of ethanolic extracts made of mushroom mycelia developed in submerged culture. Sci Bull F Biotechnol 2017;21:159-64.

33. Senthilkumar V, Sathishkumar G, Sivaramakrishnan S, Sujatha K, Razia M. Evaluation of phytoconstituents, in vitro antioxidant and antimicrobial activities of edible white button mushroom Agaricus bisporus. Int J Pharm Pharm Sci 2016;8:67-71.

34. Sánchez-Camargo AP, Herrero M. Rosemary (Rosmarinus officinalis) as a functional ingredient: Recent scientific evidence. Curr Opin Food Sci 2017;14:13-9.

35. Natarajan N, Thamaraiselvan $R$, Lingaiah $H$, Srinivasan $P$, Periyasamy BM. Effect of flavonone hesperidin on the apoptosis of human mammary carcinoma cell line MCF-7. Biomed Prev Nutr $2011 ; 1: 207-15$ 